\title{
História, desenvolvimento e ensino da Ciência Política no Brasil e na América Latina
}

\author{
History, development and teaching of Political Science \\ in Brazil and Latin America
}

\section{Historia, desarrollo y enseñanza de la Ciencia Política en Brasil y en América Latina}

\author{
Rafael Machado Madeira ${ }^{1}$ \\ (1) Adriano Codato ${ }^{2}$ \\ (1) Pablo Alberto Bulcourf
}

Wa última década e meia, estudos sobre o desenvolvimento da Ciência As compilações mais abrangentes até aqui são os volumes organizados por Freidenberg (2017) e Roqueñi, Valverde y Gutiérrez (2019). O aumento da produção evidencia o aprofundamento de estudos descritivos, mas também de pesquisas mais ambiciosas teórica e metodologicamente. Outro efeito salutar desse desenvolvimento foi o aumento contínuo do número de investigadores debruçados sobre o tema.

Um inventário superficial de títulos dessa produção recente poderia mencionar a multiplicidade de frentes de pesquisa abertas a partir de 2010 sobre: a questão de gênero na disciplina (Martin, 2013; Freidenberg, 2018), a dinâmica da publicação científica (Altman, 2005, 2012; Nicolau e Oliveira, 2016; Salatino, 2018), as fronteiras disciplinares (Leite, Codato e Perissinotto, 2018; Perissinotto, Codato e Leite, 2018) e geográficas (Botelho e Damasceno, 2016) da Ciência Política, a formação acadêmica (Bentancur e Mancebo, 2017) e o ensino da disciplina (Bulcourf, 2008; Bulcourf e Cardozo, 2012; Barberia, Godoy e Barboza, 2014); sua história

\footnotetext{
Pontifícia Universidade Católica do Rio Grande do Sul (Pucrs, Porto Alegre, RS, Brasil).

2 Universidade Federal do Paraná (Curitiba, PR, Brasil).

${ }^{3}$ Universidad Nacional de Quilmes (UNQ, Buenos Aires, Argentina) e Universidad de Buenos Aires (UBA, Buenos Aires, Argentina).
}

autores.dados_biográficos

Civitas, Porto Alegre, v. 19, n. 3, p. 489-503, set.-dez. 2019

Este artigo está licenciado sob forma de uma licença Creative Commons Atribuição 4.0 Internacional, que permite uso irrestrito, distribuição e reprodução em qualquer meio, desde que a publicação original seja corretamente citada. 
intelectual (Keinert e Silva, 2010; Leite, 2017; Limongi; Almeida; Freitas, 2016) e seus vieses temáticos no Brasil (Tavares e Oliveira, 2016); ou sobre a circulação internacional da produção dos cientistas políticos (Altman, 2012; Madeira e Marenco, 2016).

Argentina, Brasil, Colômbia e México já acumulam relevantes esforços para dar conta de suas histórias nacionais. Sobre a Argentina, destaca-se a reconstrução das ideias políticas que explicam a organização nacional e a constituição do campo da Ciência Política a partir do "Centenário de 1910" (Bulcourf e D’Alessandro, 2003; Fernández, 2002; Bulcourf e Cardozo, 2013). No Brasil, trabalhos discutidos no âmbito de reuniões da Anpocs e da ABCP permitiram dar conta da constituição da dinâmica disciplinar, suas relações com as demais ciências sociais e seus principais eixos temáticos (Miceli, 1999; Avritzer; Milani; Braga, 2016; Martins, 2005; Trindade, 2012). No caso da Colômbia, a ACCPol editou um estudo que analisa o desenvolvimento disciplinar por muitos ângulos. No âmbito da Universidad del Tolima realizaram-se estudos com importante balanço crítico sobre o campo da Ciência Política (Leyva Botero, 2013; Caicedo e Cuellar, 2015). No que tange ao México destaca-se uma série de estudos detalhados sobre as diferentes instituições nas quais se praticou e se ensinou a Ciência Política, bem como, sobre seus subcampos disciplinares (Alarcón Olguín, 2011; Reveles Márquez, 2012; Barrientos Del Monte, 2017).

Também os estudos comparados sobre a história da Ciência Política avançaram significativamente, o que é importante para se estabelecer parâmetros comuns para a análise dos diferentes graus de desenvolvimento disciplinar na região, é um avanço substantivo para a consolidação desse programa de pesquisas (Altman, 2005; Cardozo, 2011; Bulcourf; Gutiérrez Márquez; Cardozo, 2014; Barrientos Del Monte, 2014). A consolidação dessa agenda se reflete, por exemplo, na retomada, dez anos depois, em 2015, de dossiê temático da Revista de Ciencia Política, da Universidad Católica de Chile. Para além dos trabalhos pontuais, é aqui que surge a primeira reflexão sobre a trajetória do próprio campo na até aquele período (Bulcourf, Gutiérrez Márquez e Cardozo, 2015).

Ao menos em cinco oportunidades, periódicos de diferentes países da região organizaram dossiês sobre o tema. Além dos dois números publicados pela Revista de Ciencia Política (2005, 2015), cabe menção ao número de 2012 de Política: Revista de Ciencia Politica, da Universidad de Chile, à publicação, em 2013, de dossiê na revista Debates, da Universidade Federal do Rio Grande do Sul, ao dossiê da Revista Andina de Estudios Políticos, vinculada ao Instituto de Estudios Andinos del Perú, 
e publicada em 2016. Finalmente, na Europa, Polônia também dá vazão a essa agenda com a publicação, em 2017, do Anuario Latinoamericano da Universidade Marie Curie-Skolosowskiej. Essa sequência de dossiês especiais sobre a história e o desenvolvimento da disciplina na América Latina constitui-se em importante roteiro a partir do qual esse campo de estudos vem ganhando corpo.

Paralelamente ao aumento da publicação de livros e artigos nos últimos quinze anos, esse desenvolvimento se materializou e foi intensificado a partir de 2012 com a criação do Grupo de investigação sobre a história da Ciência Política na América Latina (GIHCPOLAL), como grupo de trabalho permanente da Associação Latino-Americana de Ciência Política (Alacip). No âmbito das associações nacionais de Ciência Política, destaque-se também a criação de grupos de trabalho específicos na Associação Brasileira de Ciência Política (ABCP), na Sociedad Argentina de Análisis Político (Saap), na Associación Colombiana de Ciencia Política (ACCPol), na Associación Mexicana de Ciencias Políticas (Amecip), entre outras. No México também se organizaram os Coloquios Historia y Balance de la Ciencia Política em México (com quatro eventos já realizados). E, desde 2017, o grupo Ágora da Universidad del Cauca tem realizado anualmente os Encontros Internacionais de Ciência Política, centrados na história e no avanço da disciplina. Tal evento ocorre justamente na cidade colombiana de Popayán, que dá nome ao Manifesto que resume um conjunto de necessidades e de perspectivas para a investigação da Ciência Política na América Latina.

Por fim, a recente criação do grupo sobre Historia y desarrollo de la Ciencia Política en Iberoamérica, na Associación Española de Ciencia Política y de la Administración (AECPA), possibilitará a constituição de redes de pesquisa e de colaboração entre investigadores dos diversos países latinoamericanos com seus pares em Portugal e Espanha. Esse processo crescente de articulação de múltiplas redes de colaboração entre pesquisadores engajados no tema teve na publicação do Manifesto de Popayán (ver no final deste texto), lançado no encontro da Associación Colombiana de Ciencia Política em 2014, um passo importante.

O Manifesto de Popayán destaca-se por dois elementos importantes. Por um lado, marca uma nova etapa nos estudos sobre história, evolução e ensino da Ciência Política na América Latina, buscando um olhar mais amplo, mais crítico e mais reflexivo. Por outro lado, atua como uma agenda de pesquisas que, sem aderir a nenhuma tradição específica, propõe a realização de análises profundas e em diálogo com outras disciplinas e áreas do conhecimento, como a Epistemologia, a História da Ciência, a Sociologia, a Antropologia (essas 
duas últimas, no geral, mais atentas à análise de suas histórias disciplinares). Defende, também, um olhar menos inocente acerca do "fazer científico" e de como se constituem o prestígio e a distribuição de recursos, contribuindo para colocar as relações de poder dentro da própria Ciência Política. Outro aspecto central é a sua potencialidade para articular pesquisadores da região em torno da temática, o que pode fazer dessa nova área uma contribuição importante internacionalmente.

Com o propósito de fomentar ainda mais o debate acerca do progresso da disciplina no Brasil e na América Latina, este dossiê reúne artigos e resenhas que analisam os processos de estruturação da Ciência Política e sua relação tanto com disciplinas afins como com os demais aspectos da vida social. Isso feito a partir de diversos temas, diferentes enfoques e de variadas abordagens e técnicas de pesquisa.

Os textos do dossiê abordam questões que representam sérios desafios e são, ao mesmo tempo, campos riquíssimos de possibilidades quando o que está em jogo é a análise reflexiva e a produção de conhecimento autóctone sobre o desenvolvimento da Ciência Política. Isto posto, a ambição deste dossiê é a de ser mais um espaço para que cientistas sociais que estudam a configuração e a transformação da Ciência Política na América Latina possam dialogar entre si e com a literatura pertinente a partir tanto de uma perspectiva interdisciplinar como geográfica.

Bourdieu (1975), ao analisar a luta pela definição legítima do que é ciência, postula que não faria sentido tentar distinguir as determinações sociais das determinações propriamente científicas das práticas científicas. Ao criticar a concepção de que a ciência poderia ser analisada a partir, por exemplo, de uma "lógica imanente", afirma que:

Uma ciência genuína da ciência só pode ser constituída se rejeitar radicalmente a oposição abstrata (que também é encontrada em outro lugar, na história da arte, por exemplo) entre uma análise imanente ou interna, que se enquadra diretamente no domínio da epistemologia e que restauraria a lógica segundo a qual a ciência gera seus próprios problemas; e uma análise externa, que relaciona esses problemas às suas condições sociais de aparecimento (Bourdieu, 1975, p. 94, tradução nossa). ${ }^{1}$

\footnotetext{
${ }^{1}$ Do original: Une science authentique de la science ne peut se constituer qu'à condition de récuser radicalement l'opposition abstraite (qui se retrouve aussi ailleurs, en histoire de l'art par exemple) entre une analyse immanente ou interne, qui incomberait en propre à l'épistémologie et qui restituerait la logique selon laquelle la science engendre ses propres problèmes, et une analyse externe, qui rapporte ces problèmes à leurs conditions sociales d'apparition.
} 
A interação com diferentes dimensões da vida social, econômica, cultural e política é importante para que se possa compreender o quanto o campo acadêmico é estruturado também por tais esferas em cada contexto nacional (Heilbron, 2006, 2008, 2012; Bourdieu, 2001). Através dessas interconexões, podemos problematizar, por exemplo, a noção de que as estratégias de construção de reputações e de manutenção de carreiras acadêmicas miram somente o mundo acadêmico. A recorrência de casos de politólogos que circulam entre o universo acadêmico e posições importantes na imprensa, em governos e em partidos políticos - e que reconvertem esses trunfos em prestígio que impacta, por sua vez, o campo acadêmico novamente (Miceli, 1989; Ravecca, 2019) - atesta a porosidade e a conexão entre a ciência e as esferas extracientíficas.

O conjunto de textos que compõem o dossiê permite problematizar uma série de aspectos da Ciência Política como prática científica, através da objetivação de posições de desigualdade das mais diversas naturezas. Essas posições são descritas e analisadas a partir do confronto entre múltiplos polos (dominante versus dominado, centro versus periferia, masculino versus feminino, branco versus não branco, pesquisa versus ensino, internacional versus nacional, capital versus interior, pós-graduação versus graduação, programas consolidados versus programas recentes etc.) que perpassam e influenciam o desenvolvimento da disciplina.

O esforço de identificação e de objetivação dessas (e de inúmeras outras) desigualdades é crucial para que se possa conceber a disciplina como um campo de conflito entre diferentes definições do que seja a Ciência Política mais "legítima", bem como das propriedades e características mais valorizadas no interior desse universo.

É comum orientações teórico-metodológicas terem o projeto claro de definir ou unificar a disciplina, como abordagens como o behavioralism, a escolha racional e, agora, o neoinstitucionalismo, no contexto da Ciência Política estadunidense. A abordagem dominante, portanto, envolve uma ordem acadêmica, além de propriamente intelectual, que define a disciplina e é determinante na definição de seu futuro. [...] Aliás, não há correspondência necessária entre eficácia heurística ou consistência lógica e a institucionalização ou a maior valorização de uma abordagem. Não só pode haver divisões epistemológicas fundamentais, como a hierarquia é influenciada por uma série de estratégias, uma espécie de política acadêmica relativamente independente do embate puramente intelectual, para não falar dos modismos e dos jogos de distinção que também acometem o campo acadêmico (Leite, 2015, p. 142-143). 
A análise acerca do quanto aspectos extra-acadêmicos ajudam a compor o campo acadêmico e influenciam na produção de conhecimento, nas possibilidades de ingresso e de prosseguimento de carreiras, na sedimentação de hierarquias internas, de programas de pesquisas, na possibilidade de construção e consagração de reputações (pessoais e institucionais) é um aspecto crucial para que se possa compreender as interações entre politólogos e politólogas na região.

Os textos que formam este dossiê abordam e articulam várias dessas questões a partir de dados empíricos originais. As análises permitem ao leitor montar um mosaico no qual vários dos pontos anteriormente elencados são mencionados.

Seguindo de forma clara as diretrizes do Manifesto de Popayán, Sergio Angel Baquero, Juan Carlos Rico Noguera e Julián Andrés Caicedo Ortiz questionam os limites da importação do conceito de "institucionalização", que pressuporia a adesão à definição mainstream da Ciência Política norteamericana. Os autores evidenciam o quanto a incorporação acrítica de esquemas analíticos e de critérios de avaliação institucional formulados em outros contextos pode ser problemática. Essa crítica abre espaço para que se explore, no futuro, o conceito alternativo, proposto pelos autores, de "desenvolvimento situado", relacionando-o à literatura já acumulada acerca da história da ciência em geral e das Ciências Sociais, em particular. ${ }^{2}$

$\mathrm{O}$ artigo de André Marenco é bastante inovador e permite problematizar a relação entre Ciência Política e demais campos profissionais, já que toca em um aspecto crucial para o desenvolvimento de carreiras: o valor prático de um título de pós-graduação no Brasil. Os altos salários identificados na análise são resultado da alta valorização pecuniária dos títulos de Ciência Política no mercado. Por outro lado, tal fenômeno pode ser também explicado pelo fato de que a Ciência Política atrai um perfil discente já bem inserido no próprio mercado não acadêmico ou na burocracia estatal. Essa descoberta abre um campo alternativo de estudos sobre a capacidade de atração que a Ciência Política exerce não apenas sobre estudantes que almejam a docência, mas também sobre profissionais em pleno desenvolvimento de suas

\footnotetext{
${ }^{2}$ Via de regra, quando se fala em Ciência Política "norte-americana", defensores e críticos tendem a centrar suas análises na ortodoxia do campo. O que faz sentido dada a sua influência em âmbito internacional. Por outro lado, esse foco pode fazer com que o leitor não especializado confunda e tome o polo mainstream como o próprio campo da Ciência Política (reforçando, justamente, o polo dominante no interior do campo). É importante enfatizarmos os intensos debates e os jogos de força existentes no interior da Ciência Política norte-americana (Monroe, 2005) a fim de matizar o debate em torno da recepção da "Ciência Política norte-americana" em nossa região.
} 
carreiras e que identificam, na pós-graduação, uma possibilidade de aumento salarial e/ou de maior projeção profissional.

Os artigos de Rafael Machado Madeira e Cecília Rocha Carpiuc e de Márcia Rangel Candido, João Feres Júnior e Luiz Augusto Campos permitem problematizar o quanto desigualdades de gênero e de raça se manifestam na Ciência Política. Ambos os artigos trazem uma importante dimensão comparativa: Madeira e Carpiuc analisam desigualdades de gênero em dois países da região (Brasil e Uruguai) e em duas dimensões importantes na progressão de carreiras (produção e formação acadêmica); Candido e seus colaboradores examinam desigualdades de gênero e raça na Ciência Política brasileira em comparação com a Sociologia e a Antropologia. Os dois artigos mapeiam e descrevem padrões. A partir desses mapeamentos, ambos os trabalhos apontam para a necessidade de incorporar uma perspectiva mais explicativa, que busque abordar as causas dos fenômenos, tentando descobrir e revelar as dinâmicas a partir das quais essas desigualdades se reproduzem.

Por também possuir uma dimensão descritiva e comparativa, as considerações anteriores são aplicáveis ao texto de Rodrigo Rossi Horochovski, Augusto Junior Clemente, Rafael Cardoso Sampaio e Ricardo Fabrino Mendonça. Ao revelar a importância crescente da democracia deliberativa na agenda de investigações da Ciência Política brasileira (em comparação com outras disciplinas), o artigo mapeia, de forma detalhada, as conexões entre quem produz, quando produz e onde são publicadas as pesquisas sobre o tema nos periódicos brasileiros.

O dossiê traz também dois artigos que analisam aspectos da configuração da Ciência Política em dois estados importantes da federação e fora do eixo Rio de Janeiro - São Paulo. O artigo de Rayza Sarmento, Daniela Leandro Rezende e Hilton Felippe dos Santos Júnior permite a problematização de uma série de desigualdades ainda pouco examinadas pela literatura no que tange à produção sobre a Ciência Política brasileira. Duas merecem destaque aqui: a menor valorização do ensino em relação à pesquisa e da graduação em relação à pós-graduação. Esses temas podem permitir mais pesquisas comparadas, dado que revelam diferentes padrões de autonomização da Ciência Política na América Latina (via cursos de graduação ou de pós-graduação). Por fim, o artigo de Cristiana Maglia e Paulo Sérgio Peres permite aprofundar um aspecto presente no texto sobre a Ciência Política mineira, mas que adquire uma importância central na análise do caso sul-rio-grandense: a baixa interiorização da disciplina no Brasil.

Completam o dossiê duas resenhas bibliográficas. Uma delas aborda a Ciência Política como intrincado campo de "saber-poder". A resenha do livro 
de Paulo Ravecca, The politics of Political Science, destaca a constituição no Chile de Pinochet de uma Ciência Política autoritária, e no Uruguai pós-transição do regime ditatorial-militar, de uma disciplina diferente, não autoritária, mas conformista, política e intelectualmente. A outra resenha enfoca "as ideias sobre as ideias" de um dos founding fathers da Ciência Política no Brasil, Wanderley Guilherme dos Santos. O livro A imaginação política brasileira é uma compilação de cinco estudos do autor sobre o pensamento político e social produzido no Brasil no século 20. Mas esses ensaios podem ser lidos, também, como uma história intelectual do próprio Santos e de seu papel pioneiro na constituição de um campo institucional de pesquisas sobre o pensamento político brasileiro.

Em resumo, os organizadores deste dossiê buscaram fomentar a discussão acerca do ensino e da pesquisa em Ciência Política; incentivar a publicação de análises comparativas com as demais ciências sociais; dar continuidade ao debate sobre a história da autonomização da Ciência Política em âmbito nacional e em perspectiva comparada; e articular trabalhos que partam de diferentes abordagens sobre a disciplina, instigando a pluralidade de técnicas de pesquisa, referências teóricas e dados analisados.

Avaliamos que o dossiê atinge em grande medida esses objetivos. Contudo, uma das principais lacunas que se evidenciam é a pouca presença de análises que tomem a América Latina como um todo (à exceção do artigo de Sergio Angel Baquero, Juan Carlos Rico Noguera e Julián Andrés Caicedo Ortiz), ou que busquem comparar o desenvolvimento da disciplina a partir da análise em distintos países da região (à exceção do artigo de Rafael Machado Madeira e de Cecília Rocha Carpiuc). Isso permite chamar a atenção de politólogos e politólogas sobre a importância do fortalecimento de um olhar mais abrangente e que analise o desenvolvimento da Ciência Política levando em consideração as fronteiras entre os países da região. ${ }^{3}$

É crucial incentivar, ainda mais, esse temário de pesquisas, ampliando seu escopo, área geográfica, dimensão comparativa e, em especial, capacidade analítica. Uma vez tendo avançado na dimensão descritiva da configuração e desdobramento histórico e institucional da Ciência Política (o que aconteceu?), um passo seguinte, mais do que necessário, é incorporar a dimensão explicativa (por que aconteceu assim?) das múltiplas configurações da disciplina na América Latina, o Brasil incluído.

\footnotetext{
${ }^{3}$ Para a discussão sobre o paroquialismo da Ciência Política brasileira, ver, por exemplo, Marenco (2014) e Amorin Neto e Santos (2015).
} 


\section{Referências}

ALARCON OLGUIN, Víctor. La Ciencia Politica en México: trayectorias y retos de su enseñanza. México: Torres y asociados, 2011.

ALTMAN, David. La institucionalización de la Ciencia Política en Chile y América Latina: una mirada desde el Sur. Revista de Ciencia Política, Santiago, v. 25, n. 1, p. 3-15, 2005.

ALTMAN, David. Where is knowledge generated? On the productivity and impact of political science departments in Latin America. European Political Science, [S. l.], n. 11, p. 71-87, 2012.

AMORIN NETO, Octavio; SANTOS, Fabiano. La Ciencia Política en Brasil en la última década: la nacionalización y la lenta superación del parroquialismo. Revista de Ciencia Politica, Santiago, v. 35, n. 1, p. 19-31, 2015.

AVRITZER, Leonardo; MILANI; Carlos, BRAGA, María do Socorro (org.). A ciência política no Brasil 1960-2015. Rio do Janeiro: FGV Editora y ABCP, 2016.

BARBERIA, L. G., GODOY, S. R. de; BARBOZA, D. P. Novas perspectivas sobre o "calcanhar metodológico": o ensino de métodos de pesquisa em Ciência Política no Brasil. Teoria \& Sociedade, Belo Horizonte, v. 22, n. 2, p. 156-184, 2014.

BARRIENTOS DEL MONTE, Fernando. Buscando una indentidad. Breve historia de la Ciencia Política en América Latina. México: Fontamera-UG, 2014.

BARRIENTOS DEL MONTE, Fernando (org.). Historia y balance de la Ciencia Política en México. México: Tirant lo Blanch, 2017.

BETANCUR, N.; MANCEBO, M. E. ¿Cómo se forma a los científicos políticos en Iberoamérica? Análisis de la oferta de titulaciones de grado en Ciencia Política en doce países. Revista Española de Ciencia Política, [S. l.], n. 43, p. 161-185, 2017. Disponível em: 10.21308/recp.43.07. Acesso em: 09 out. 2019.

BOTELHO, J. C. A.; DAMASCENO, J. P. T. Pesquisa e produção de conhecimento sobre a América Latina na Ciência Política brasileira. Revista Brasileira de Ciência Política, Brasília, DF, n. 19, p. 121-145, 2016.

BOURDIEU, Pierre. La spécificité du champ scientifique et les conditions sociales du progrès de la raison. Sociologie et sociétés, Montreal, CA, v. 7, n. 1, p.91-118, 1975.

BOURDIEU, Pierre. Science de la science et réflexivité: cours du Collège de France 2000-2001. Paris: Raisons d'agir, 2001.

BULCOURF, Pablo. Algunas reflexiones sobre la enseñanza de la ciencia política en la Argentina. PostData, [S. l.], n. 13, p. 225-242, 2008. 
BUlCOURF, Pablo; CARDOZO, Nelson. La enseñanza de la Ciencia Política en las universidades Latinoamericanas: apuntes para una agenda de desarrollo. Universidades, México, n. 53, p. 4-14, 2012.

BUlCOURF, Pablo; CARDOZO, Nelson. La Ciencia Política en la Argentina: su desarrollo e institucionalización. Revista Debates, Porto Alegre, v. 7, n. 3, p.57-88, 2013.

BULCOURF, Pablo; D’ALESSANDRO, Martín. La Ciencia Política en la Argentina. In: PINTO, Julio (org.). Introducción a la Ciencia Política. Buenos Aires: Eudeba, 2003.

BULCOURF, Pablo; GUTIÉRREZ MÁRQUEZ, Enrique; CARDOZO, Nelson. El desarrollo de la Ciencia Política en Argentina, Brasil. Anuario Latinoamericano, [S. l.], v.1, n.1, p. 155-184, 2014.

BUlCOURF, Pablo; GUTIÉRREZ MÁRQUEZ, Enrique; CARDOZO, Nelson. Historia y desarrollo de la Ciencia Política en América Latina: reflexiones sobre la constitución del campo de estudios. Revista de Ciencia Política, Santiago, v. 35, n. 1, p. 179-199, 2015. Disponível em: 10.4067/S0718-090X2015000100009. Acesso em: 09 jun. 2019.

CARDOZO, Nelson. Del Centenario al bicentenario: algunas reflexiones sobre el desarrollo de la ciência política em los países del Cono Sur. Revista Argentina de Ciencia Política, Buenos Aires, n. 23/24, p. 221-253, 2011.

CAICEDO, Julián; CUELLAR, Julián (org.). ¿Hacia donde va la ciência politica? Algunas reflexiones sobre la disciplina em Colombia. Ibagué: Unitolima, 2015.

FERNANDEZ, Arturo (org.). La Ciência Politica en la Argentina. Dos siglos de historia. Buenos Aires: Biebel: 2002.

FREIDENBERG, F. (org.). La Ciencia Política sobre América Latina: docencia e investigación en perspectiva comparada. Santo Domingo: Fundación Global Democracia y Desarrollo-FUNGLODE, 2017.

FREIDENBERG, F. Gender blindness in Latin American Political Science. Ameryka Lacińska, [S. l.], v. 3, n. 101, p. 50-66, 2018.

HEILBRON, Johan. Naissance de la Sociologie. Marseille: Agone, 2006.

HEILBRON, Johan. Qu'est-ce qu'une tradition nationale en Sciences Sociales? Revue d'Histoire des Sciences Humaines, [S. l.], n. 18, p. 3-16, 2008.

HEILBRON, Johan. A Ciência Social europeia como campo transnacional de pesquisa. Mana, Rio de Janeiro, v. 18, n. 2, p. 289-307, 2012. 
KEINERT, F. C.; SILVA, D. P. A gênese da Ciência Política brasileira. Tempo Social, São Paulo, v. 22, n. 1, p.79-98, 2010. Disponível em: 10.1590/S010320702010000100005 . Acesso em: 09 jun. 2019.

LEITE, Fernando. O campo de produção da Ciência Política brasileira contemporânea: uma análise histórico-estrutural de seus princípios de divisão a partir de periódicos, áreas e abordagens. 2015. 273 f. Tese (Doutorado em Sociologia) - Programa de PósGraduação em Sociologia, Departamento de Sociologia e Ciência Política, Setor de Ciências Humanas, Letras e Artes, Universidade Federal do Paraná, Curitiba, 2015. Disponível em: https://acervodigital.ufpr.br/bitstream/handle/1884/37966/R\%20-\%20 T\%20-\%20FERNANDO\%20LEITE.pdf?sequence=3\&isAllowed=y. Acesso em: 09 jun. 2019.

LEITE, Fernando. Tradições intelectuais na Ciência Política brasileira contemporânea. Dados, Rio de Janeiro, v. 60, n. 3, p.751-791, 2017. Disponível em: 10.1590/001152582017134. Acesso em: 09 jun. 2019.

LEITE, F.; CODATO, A.; PERISSINOTTO, R. Midiendo el capital académico de la ciencia política y la sociología política producida en Brasil. Anuario Latinoamericano: Ciencias Politicas y Relaciones Internacionales, [S. l.], n. 5, p. 61-79, 2018. Disponível em: 10.17951/al.2017.5.61. Acesso em: 09 jun. 2019.

LEYVA BOTERO, Santiago (org.). La Ciencia Política em Colombia: ¿una disciplina en institucionalización? Medellín: ACCPol-Eafit, 2013.

LIMONGI, F., ALMEIDA, M. H. T. de; FREITAS, A. Da sociologia política ao (neo)institucionalismo: trinta anos que mudaram a Ciência Política no Brasil. In: L. Avritzer, C. R. S. Milani, M. do S. Braga (org.). A ciência politica no Brasil: 19602015. Rio de Janeiro: FGV Editora, 2016. p. 61-91.

MADEIRA, R. M.; MARENCO, A. Os desafios da internacionalização: mapeando dinâmicas e rotas da circulação internacional. Revista Brasileira de Ciência Política, Brasília, DF, n. 19, p.47-74, 2016. Disponível em: 10.1590/0103-335220161903. Acesso em: 09 jun. 2019.

MARENCO, André. The three Achilles' heels of brazilian Political Science. Brazilian Political Science Review, São Paulo, v. 8, n. 3, p. 3-38, 2014.

MARTIN, María Elena. El lugar de los estudios de género en la Ciencia Politica Argentina. In: CONGRESO NACIONAL DE CIENCIA POLÍTICA, 11., 2013, Paraná. Anais eletrônicos [...]. [S. l.: s. n.], 2013.

MARTINS, Carlos B. (org.). Para onde vai a pós-graduação em Ciências Sociais no Brasil. Bauru: Editora Edusc, 2005.

MICELI, Sergio (org.). História das Ciências Sociais no Brasil. São Paulo: Idesp/ Vértice/Finep, 1989. 
MICELI, Sergio (org.). O que ler na ciência social brasileira 1970-1995. São Paulo: Sumaré/Anpocs, 1999. (Ciência Política, v. 3).

MONROE, Kristen Renwick (org.). Perestroika!: the raucous rebellion in Political Science. New Haven; Connecticut: Yale University Press, 2005.

NICOLAU, J.; OLIVEIRA, L. Political Science in Brazil: an analysis of academic articles (1966-2015). Sociologia e Antropologia, Rio de Janeiro, v. 7, n. 2, p. 371-393, 2016. Disponível em: 10.1590/2238-38752017v723. Acesso em: 09 jun. 2019.

PERISSINOTTO, R.; CODATO, A.; LEITE, F. Opostos determinantes: a Sociologia Política brasileira no século XXI. In: MICELI, Sérgio; MARTINS, Carlos Benedito (org.). Sociologia brasileira hoje II. Cotia: Ateliê Editorial, 2018. p. 19-63.

RAVECCA, Paulo. The politics of Political Science. Re-Writing Latin American Experiences. New York: Routledge, 2019.

REVELES MARQUEZ, Francisco (org.). La Ciência Politica em México, hoy: ¿qué sabemos? México: Plaza y Valdés, 2012.

ROQUEÑI, María del Carmen; VALVERDE, Karla; GUTIÉRREZ Enrique (org.). La Ciência Politica: disciplina académica, profesionalización y nuevos horizontes. México: Universidad Iberoamericana, 2019.

SALATINO, M. La circulación de la ciencia política en América Latina. Revistas, indexadores y circuitos de publicación. Anuario Latinoamericano: Ciencias Políticas y Relaciones Internacionales, [S. l.], v. 5, n. 207, 2018. Disponível em: 10.17951/ al.2017.5.207. Acesso em: 09 jun. 2019.

TAVARES, F. M. M.; OLIVEIRA, I. C. de. Omissões e seletividades da Ciência Política brasileira: lacunas temáticas e seus problemas sócio-epistêmicos. Revista Brasileira de Ciência Política, Brasília, DF, n. 19, p.11-45, 2016. Disponível em: 10.1590/0103-335220161902. Acesso em: 09 jun. 2019.

TRINDADE, Hélgio. Ciências Sociais no Brasil: diálogos com mestres e discípulos. Brasília: Anpocs: Liber Livro Editora, 2012. 


\section{MANIFESTO DE POPAYÁN}

\section{Os estudos sobre a história e o desenvolvimento da Ciência Política na América Latina: necessidades e perspectivas ${ }^{4}$}

Reunidos na cidade colombiana de Popayán, por ocasião do III Congresso de Ciência Política organizado pela Associação Colombiana de Ciência Política (ACCPol), queremos expressar nosso interesse nos estudos sobre a história, o desenvolvimento e o ensino da Ciência Política na América Latina. A Ciência Política na região tem experimentado um crescimento significativo, embora desigual entre os países. Tal crescimento, resultou no aumento dos cursos de graduação e pós-graduação, do número de professores e pesquisadores, dos sistemas de bolsa de estudos e pesquisa, do fomento e reconhecimento das pesquisas científicas e da publicação de vários livros e revistas especializadas, algumas delas internacionalmente reconhecidas. Também se destaca o desenvolvimento das associações nacionais a partir da realização de eventos e congressos específicos, onde paulatinamente, se intensificou a participação de colegas pesquisadores de diferentes países. Junto a isso, durante a última década, houve o incremento de trabalhos que tiveram como objeto o estudo da disciplina e de suas características. Resultando assim, entre outras coisas, da criação do Grupo de Pesquisa em História da Ciência Política na América Latina (GIHCPOLAL) da Associação Latinoamericana de Ciência Política (Alacip) na cidade de Quito no ano de 2012, assim como da realização de uma série de atividades e colóquios específicos para tratar da temática junto a grupos de trabalho e mesas especiais nos próprios congressos nacionais da disciplina.

Estes estudos, que começaram a partir de reflexões mais simples e trabalhos exploratórios foram se consolidando, permitindo assim, um maior conhecimento da história disciplinar da Ciência Política. A partir de trabalhos de cunho bibliométrico, demonstrou-se o desenvolvimento da produção editorial em revistas científicas, assim como dos indicadores das atividades institucionais de várias universidades e centros de pesquisa. Também houve a realização de pesquisas comparativas sobre o resgate da história biográfica de cientistas políticos relevantes.

Alem disso, é necessário reconhecer os aspectos "políticos" que moldam e estruturam o campo da Ciência Política e suas conseqüências na seleção das temáticas de pesquisa, de sua problematização e da adoção das teorias e estratégias metodológicas da disciplina. Essas características necessitam ser abordadas para se compreender que a atividade científica e acadêmica faz parte de um processo mais amplo de construção social, em que estão presentes os aspectos políticos, ideológicos, de diferentes interesses e visões de mundo, em que os cientistas políticos estão envoltos.

\footnotetext{
${ }^{4}$ Agradecemos a Marcelo Pinheiro Cigales pela tradução deste documento.
} 
Tendo isso por base, alguns cientistas políticos pretendem proporcionar e fomentar este tipo de trabalho convidando aos demais colegas da região a aderirem a esta iniciativa incorporando seus comentários e sugestões. Expressamos abaixo alguns elementos que consideramos importantes para continuar e aprofundar esse tipo de pesquisa e sua divulgação no campo da Ciência Política na América Latina:

1) Promover a pesquisa científica no campo de estudo sobre a história, o desenvolvimento e o ensino da Ciência Política.

2) Incrementar a troca de trabalhos, informações e experiências dentro desta modalidade de pesquisa.

3) Dar continuidade e aprofundar estudos bibliométricos incorporando novas modalidades e ampliando os bancos de dados existentes.

4) Incentivar a realização de eventos, conferências, colóquios, seminários e workshops específicos sobre a temática.

5) Promover a incorporação de cursos de graduação e pós-graduação sobre o assunto.

6) Incentivar o trabalho interdisciplinar sobre o tema, incorporando aspectos teóricos e metodológicos da epistemologia, da sociologia do conhecimento e da ciência e da história da ciência neste tipo de pesquisa.

7) Promover estudos que permitam contextualizar historicamente os trabalhos sobre o desenvolvimento da Ciência Política, analisando a interação com fatores culturais, políticos, econômicos e sociais.

8) Dotar este tipo de estudos com os conhecimentos historiográficos necessários para permitir uma maior e melhor contextualização das obras em sua dimensão histórica.

9) Superar certo caráter "paroquial" e "endogâmico" que teve uma grande parte desses trabalhos durante os primeiros anos de pesquisa, abrindo caminho para estudos mais integrais e interdisciplinares, incorporando as contribuições dos outros campos já mencionados.

10) Promover estudos sobre o ensino da Ciência Política e seus projetos curriculares.

11) Incorporar as contribuições da sociologia da educação, das ciências da educação, da teoria curricular e da psicologia da educação neste tipo de pesquisa.

12) Promover estudos comparativos dentro da especialidade.

13) Aprofundar os estudos sobre o desenvolvimento das diferentes áreas da Ciência Política, as histórias institucionais e as biografias das principais referências da disciplina na região.

14) Ampliar e aprofundar os estudos sobre a inserção profissional do cientista político, não só no campo científico-acadêmico, mas também em outras áreas profissionais.

15) Promover estudos de orientação "meta-teórico" que permitam conhecer e compreender as diferentes perspectivas teóricas e orientações metodológicas existentes na Ciência Política latino-americana. 
16) Estudar e analisar os aspectos "políticos" e as relações de poder existentes no campo da Ciência Política e seus vínculos com outros setores da sociedade.

17) Buscar fontes de financiamento para poder realizar pesquisas em larga escala.

18) Incentivar diferentes sistemas de bolsas para estudantes de graduação e pósgraduação nesta área de estudos e pesquisa.

19) Fomentar o intercâmbio e o trabalho em comum com as outras ciências sociais que também estão analisando sua história e desenvolvimento.

20) Promover um espírito crítico e reflexivo nesta área do conhecimento, conscientizando que o assunto em questão consiste em investigar nossa própria prática profissional.

Recebido em: 31/7/2019.

Aprovado em: 31/7/2019.

Publicado em: 15/12/2019.

Autor correspondente:

Rafael Machado Madeira

Av. Ipiranga, 6681, Prédio 8, 4ㅇandar, sala 403

90619-900, Porto Alegre, RS, Brasil

\section{RAFAel Machado MadeIRA <rafael.madeira@pucrs.br>}

Doutor em Ciência Política pela Universidade Federal do Rio Grande do Sul (Ufrgs, Porto Alegre, RS, Brasil). Professor do PPG em Ciências Sociais da Pontifícia Universidade Católica do Rio Grande do Sul (Pucrs, Porto Alegre, RS, Brasil) e bolsista da Capes (Proc. n. 7304/14-5).

Orcid: https://orcid.org/0000-0002-3864-7673

ADRIANO CODATO < adrianocodato@gmail.com>

Doutor em Ciência Política pela Universidade Estadual de Campinas (Unicamp, Campinas, SP, Brasil). Professor e pesquisador do Programa de Pós-Graduação em Ciência Política da Universidade Federal do Paraná (UFPR, Curitiba, PR, Brasil).

Orcid: https://orcid.org/0000-0002-5015-4273

PABlo Alberto Bulcourf < pablo_bulcourf@yahoo.com.ar>

Professor e pesquisador da Universidad Nacional de Quilmes (UNQ, Buenos Aires, Argentina) e da Universidad de Buenos Aires (UBA, Buenos Aires, Argentina).

Orcid: https://orcid.org/0000-0002-4859-2194 